\title{
The Ablation Casting Process
}

\author{
J. Grassi ${ }^{1, a}$, J. Campbell ${ }^{2}$, M. Hartlieb ${ }^{3}$ and F. Major ${ }^{4}$ \\ ${ }^{1}$ Alotech Ltd., 1448 Hedgewood LN NW, Kennesaw, GA 30152, USA \\ ${ }^{2}$ Alotech Ltd., Park Rd., West Malvern, WR14 4BJ, United Kingdom \\ ${ }^{3}$ RioTintoAlcan Inc., 1188 Sherbrooke St. W., Montréal, Québec, H3A 3G2, Canada \\ ${ }^{4}$ Rio Tinto Alcan, 945 Princess St., Kingston, Ontario, K7L 5T4, Canada \\ a ic@campbelltech.plus.com
}

Keywords: precision sand; Al casting; ablation; DAS

\begin{abstract}
A new patented casting process is described, based on a precision aggregate mold, bonded with a water-soluble binder. For the first time the twin functions of the mold (i) defining shape and (ii) providing cooling have been successfully separated allowing the production of castings of all sizes and shapes (thin and thick walls) for all $\mathrm{Al}$ and $\mathrm{Mg}$ alloys. Because solidification and cooling are separately controlled by the application of water a number of advantages follow immediately. The mold is ablated (i.e. eroded) away by the water without fume or dust and the 'air gap' is eliminated by direct contact with the water, enhancing the rate of solidification to levels normally unattainable, resulting in significantly enhanced properties. The unusual microstructures of Al-Si alloys having large DAS but micron-sized eutectic silicon indicates, in agreement with earlier predictions, that DAS per se does not control strength or ductility. The process is currently proving itself in commercial operation, having the additional advantages of modest start-up and tooling costs as well as low competitive piece part costs because of the use of low cost materials and the recycling of aggregate and water.
\end{abstract}

\section{Introduction}

The filling of aggregate mould castings and investment castings can be relatively well controlled (compared to high pressure die-casting), but the freezing rate is much lower or involves complex chilling. The mechanical properties achieved are therefore relatively poor and variable. The resin-type binder systems are major cost penalties. Additionally, during freezing of the casting, the casting contracts away from the mold, and the mold expands, opening the so-called 'air gap' between the casting and the mold. This air gap controls the rate of cooling, and thus the fineness of the microstructure and the mechanical properties of the casting.

The Ablation Casting Technology removes the aggregate mould - held together with an environmentally friendly, water soluble inorganic binder - with water, which is sprayed so as to ablate (i.e. erode by dissolution) away the mold, allowing the water to impinge directly on the casting. The technique achieves an easy removal of both the mold itself as well as the most complex internal cores, while providing a high chill rate to the casting. Directional solidification is greatly enhanced, reducing typical problems commonly associated with casting alloys outside the typical Al-Si system (for instance the AA2xx or AA6xxx series). This paper updates previous publications [1,2].

\section{Experimental}

An automotive steering knuckle in unmodified A356.2 alloy was cast into moulds made from silica sand of AFS 60 fineness, bonded with a proprietary binder based on sodium silicate. 
The melt was rotary degassed with nitrogen and brought to $730^{\circ} \mathrm{C}$. The melt was carefully transferred to the mould by hand ladle, and was poured into the mould cavity via a glass cloth screen. The mould was tilted at about 20 degrees above the horizontal during pouring into the filling basin. Immediately the temperature in the basin reached the target casting temperature $720^{\circ} \mathrm{C}$ the mould was filled by starting the rotation of the mould, lowering its angle of tilt through the horizontal, to 20 degrees below the horizontal in 5 seconds.

Ablation, using overhead water sprays at $65^{\circ} \mathrm{C}$ was immediately applied to the far ends (the coolest end) of the casting, progressing upwards along its length (Figure1), and completing the ablation of the mould and the freezing of the casting (Figure 2). The casting was fed by a feeder planted off the casting at the end of one of the relatively narrow arms. The casting at this stage was clean and cold (although the feeder retained some residual heat as can be seen from the steam issuing from the feeder sleeve in Figure 2), and ready for subsequent dressing as necessary, and heat treatment. A standard T6 heat treatment was applied.

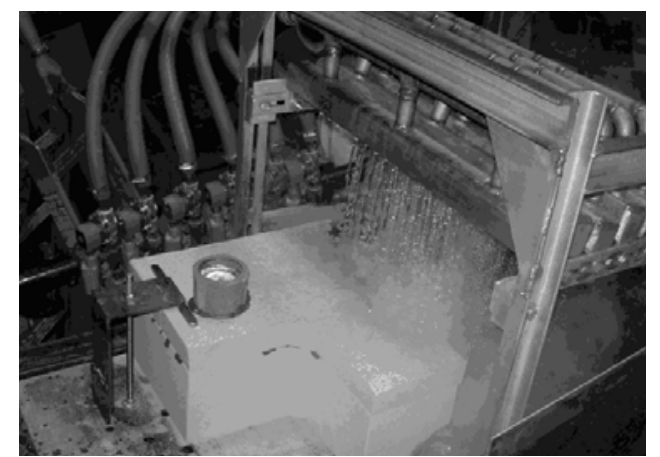

Figure 1. The ablation of the mold in progress.

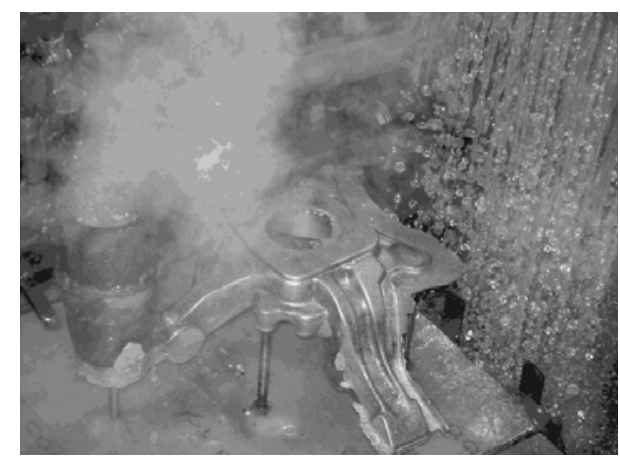

Figure 2. Ablation complete.

The optical microstructure of a test casting that was allowed to solidify without ablation is shown in Figure 3, and is typical of a non-modified Al-Si eutectic. Typical ablation-cooled structures are shown in Figures 4 and 5 illustrating limited regions of the dendrite spacing that have been refined. Figures 6 and 7 show the extreme fineness of the eutectic spacing that is difficult to resolve even at 1000 magnification in the optical microscope.

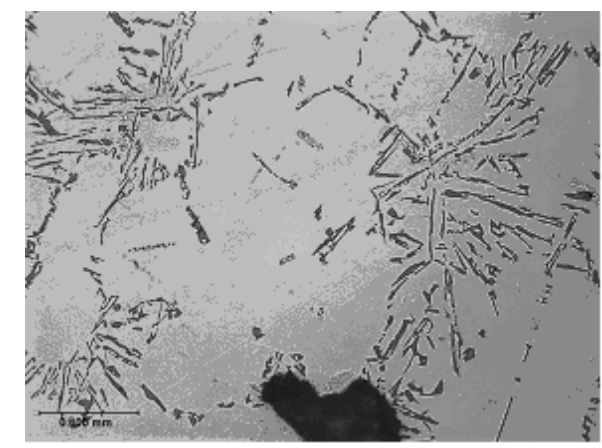

Figure 3. Unmodified and unablated structure.

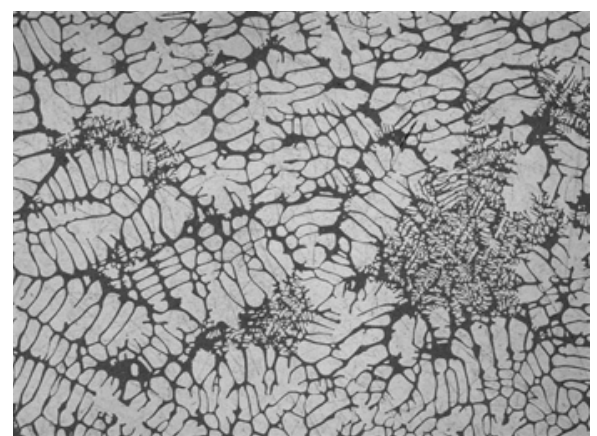

Figure 4. Mixed DAS by late ablation.

\section{Results and Discussion}

An interesting and remarkable outcome of test bars excised from the casting is not merely the enhanced mechanical properties and excellent Quality Index but also microstructural homogeneity throughout thin and thick sections. An improved casting technique such as counter-gravity filling of the mold is expected to deliver even more tightly controlled and possibly even higher properties. Table 1 describes the properties achieved in a single steering knuckle. 


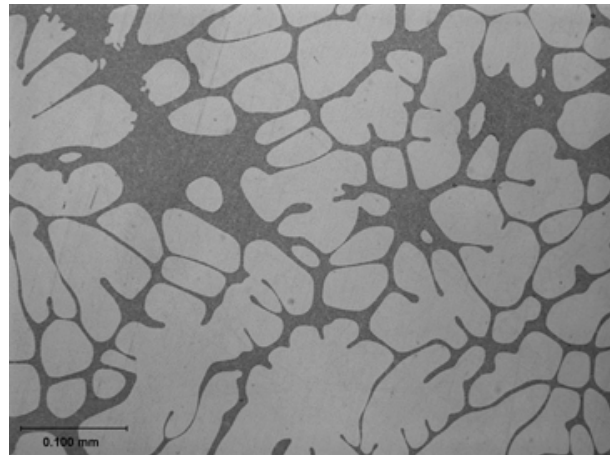

Figure 5. DAS with traces of late ablation.

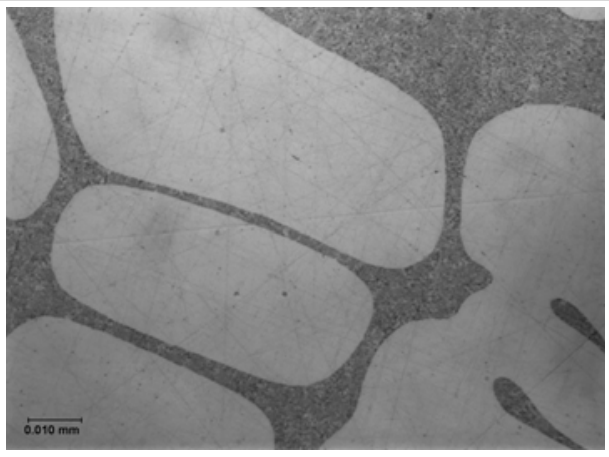

Figure 6. Eutectic phase at 1000X.

In Table 1 the mean shown for the ablatively cast knuckle was based on 7 samples taken from widely scattered and different sections of the casting. Note that the engineering error presented in Table 1 was based on the standard deviation $/ n^{1 / 2}$ where $n=7$ in this case. For design strength targets of mean minus three standard deviations high mechanical properties, and also their variance, are of utmost importance when deciding what values to design to for a given casting technology and alloy [3].

Table 1. Mechanical Properties - Ablation Cast knuckle in A356.0-T61.

\begin{tabular}{|c|c|c|c|c|}
\hline Sample Location & $\begin{array}{c}0.2 \% \text { Offset } \\
\text { Yield MPa }\end{array}$ & $\begin{array}{c}\text { Tensile Strength } \\
\text { MPa }\end{array}$ & $\begin{array}{c}\text { Elongation to } \\
\text { failure \% }\end{array}$ & $\begin{array}{c}\text { Quality } \\
\text { Index MPa }\end{array}$ \\
\hline Arm-1 & 234 & 321 & 13.5 & 491 \\
Arm-2 & 223 & 310 & 13.0 & 477 \\
Edge-1 & 230 & 322 & 14.3 & 495 \\
Under-1 & 243 & 332 & 12.1 & 494 \\
Horn-1 & 237 & 328 & 11.3 & 486 \\
Horn-2 & 234 & 322 & 12.1 & 484 \\
Hub-1 & 231 & 315 & 10.6 & 469 \\
Mean \pm & $233 \pm 2.7$ & $321 \pm 2.7$ & $12.4 \pm 0.5$ & $485 \pm 3.6$ \\
$(\sigma / \sqrt{ } \mathrm{n}) \mathrm{MPa}$ & & & & 474 \\
Mean $-3 \sigma$ & 214 & 300 & - & \\
\hline
\end{tabular}

The unique feature of ablative casting that allows for such uniformity in properties is the strong temperature gradient established through the parts being cast. An example set of thermocouple traces in a large automotive control arm is included in Figure 7.

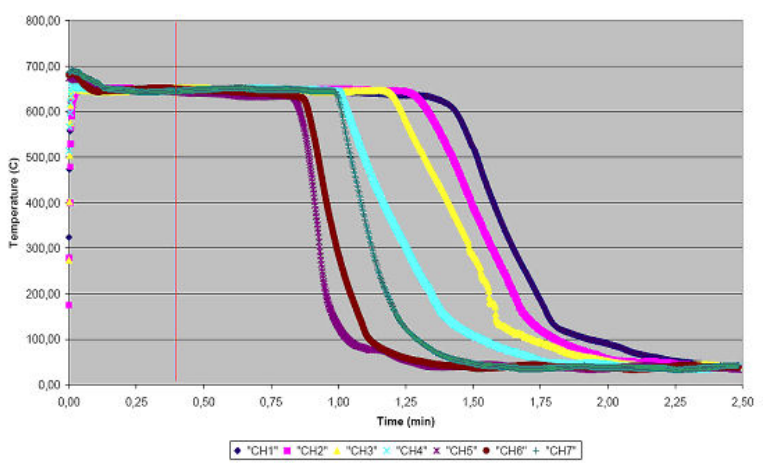

Figure 7. Example cooling curves obtained from an instrumented ablated casting. Note the large temperature differences between adjacent thermocouples only 10 or $20 \mathrm{~mm}$ apart [2]. 


\section{Current Projects}

\section{Cored Castings}

The properties of cores are proving to be a significant enabler with the new technology. The fact that the inorganic binder has minimal outgassing is a major advantage for complex cores that cannot be vented. Furthermore, the ability to simply 'wash out' even the most complex internal cores avoids the standard problems of thermal decoring where oxygen cannot easily reach some parts of the core, making binder burn-out problematic. Examples of target applications range from hollow suspension components, valve bodies, etc. up to engine cylinder heads which contain complex cores and require high properties.

\section{Thin and Thick Walled Components}

In castings to date both thin walls (2mm) and combinations of thin and thick (up to $100 \mathrm{~mm}$ ) sections have been successfully cast. This is because the mold is not intended to extract heat from the metal; the cooling fluid achieves this in a separate and controlled action. Thus the mold can either be pre-heated or be constituted from an aggregate of low thermal diffusivity selected to extract a minimal amount of heat, thus facilitating the filling of thin sections. The directional and progressive solidification towards the feeder at temperature gradients that can reach $60 \mathrm{Kmm}^{-1}$ drives effective feeding of thick sections. The technology could therefore lend itself to production of a wide variety of structural components, particularly those with hollow sections.

\section{Magnesium}

The benefits of ablation appear to extend directly to Mg-based alloys. Perhaps surprisingly, magnesium alloys have been found to be docile with respect to ablation, allowing the production of sound Mg alloy prototypes.

\section{Conclusions and Future Outlook}

The Ablation Casting process offers significant potential for a variety of components and applications in a number of different markets. The main advantages of the technology are the ability to cast complex parts combining both thin and thick sections, together with complex internal cores. It also appears possible to cast any aluminium or magnesium alloy, and achieve very good properties. We are in the process of characterizing more aluminium and magnesium alloys and optimize these for the process. Developments are in hand to enhance economy and environmental performance by the recycling of the consumables, the mold aggregate and the water.

\section{References}

[1] Grassi, J., Campbell, J., Hartlieb, M., and Major, J., “Ablation Casting”, in Aluminum Alloys: Fabrication, Characterization, \& Applications, Weimin Yin \& Subodh K. Das, eds., (TMS, the Minerals, Metals, and Materials Society, 2008), pp. 73-77.

[2] Grassi, J., Campbell, J., Hartlieb, M., and Major, J., “Ablation Casting Update”, TMS Annual Congress, Shape Casting Symposium, Los Angeles USA, 2009.

[3] GMN7152, Specification and Verification of Tensile and Fatigue Properties in Cast Components,” GM Engineering Standards (2001). 